\section{Widening the Pipeline}

\section{Julia Hartmann and Mona Merling}

The "leaky pipeline" for women in STEM, and particularly in mathematics, is a well-recognized phenomenon. Underrepresentation of women gets increasingly more glaring as you move up the academic pipeline. As an example, we can consider the University of Pennsylvania math department where we serve on the graduate admissions committee. ${ }^{1}$ Despite concerted efforts of the committee every year to increase the diversity of our graduate student population, our graduate student body at Penn reflects the dire underrepresentation of women in graduate-level mathematics. ${ }^{2}$

We have witnessed first-hand one of the main obstacles in reaching gender parity at this level: very few applications from women. Even though in the last decade academic degrees at each level (Bachelor's, Master's, and PhD) awarded to women outnumber those awarded to men, the proportion shifts when you consider the subset of degrees awarded for mathematics and statistics. The proportion shifts more and more with each higher degree, with only $29 \%$ of doctoral degrees in math going to females. Women choose a different path along the way, and this is reflected in the graduate application pool we see every year.

Eventually we realized that we needed to make an effort to encourage women to apply to graduate school before the graduate admissions season, and also to reiterate our department's commitment to diversity. This is how the idea of

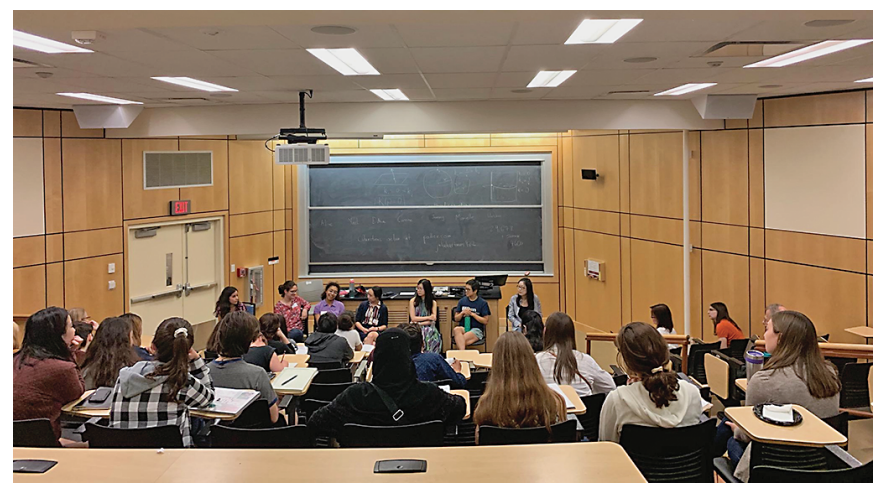

Figure 1. Participants are listening to graduate student panelists.

Julia Hartmann is a professor of mathematics at the University of Pennsylvania. Her email address is hartmann@sas. upenn. edu.

Mona Merling is an assistant professor of mathematics at the University of Pennsylvania. Her email address is mmer1ing@upenn. edu.

${ }^{1}$ Julia Hartmann has served as graduate admissions chair resp. graduate chair for four years, and Mona Merling has served as a member on the graduate admissions committee for two years.

${ }^{2}$ The composition of the incoming class is the most diverse yet, with a third of new graduate students being women and a third being part of underrepresented minority groups.

DOI: https://dx.doi.org/10.1090/noti2180
WOMAN UP, "Workshop on Math Advice and Networking at the University of Pennsylvania," was born. The blueprint was simple: a one-day event hosted by our department, targeted at female undergraduates from various institutions, meant to encourage them to consider graduate school in mathematics.

We thought about what would be most helpful and attractive to female undergraduates. Our primary goals were to give them a sense of what a career in math could look like, provide role models, and help them build a network at the crucial time when they might have to make a decision about whether to apply for graduate schools. Some of the barriers in pursuing academic careers for women certainly come from the difficulty of balancing the stress of going from being a graduate student, to having one or more postdocs, to a tenure track job-including having to move several times-with family life. Participants in this workshop got to also hear the happy side of the story from accomplished female mathematicians who have emerged successfully at the end of the pipeline: that there is also a lot of flexibility in academia when it comes to managing your time and work, which allows one to combine duties and leisure or family time in ways other jobs do not. They got to hear personal accounts about how great it is to be able to go with your kids to summer camps and still be able to work on your math research and other academic tasks there. We hope that these kinds of perspectives shed light on some of the positive aspects of life as a career mathematician vis-à-vis balancing work and family responsibilities.

Another central aspect of the workshop was to give the undergraduate participants useful advice that would improve their grad school applications, whether this season or in the future. During the workshop, the participants had the chance to talk to faculty on graduate admissions committees who could explain what they are looking for when they read applications to their programs. We wanted the applicants to also see the perspective of the people on the other side of a process which can seem mysterious.

The program had a number of different components. In addition to talks on How to pick a grad school and what you can do before you apply (Angela Gibney, Rutgers University) and a math talk given by former Penn grad student Anusha Krishnan (now at Syracuse University), there were talks by Mona Merling and David Harbater (both at the University of Pennsylvania) on aspects of applications and admissions. The most successful part, according to the participants' feedback, was a panel on grad student life (with grad students from Penn and Rutgers), where participants could ask their questions directly to the panel or submit them anonymously to a webpage. The day ended with a session on personal statements and letters of recommendation. Participants who were already preparing applications had the chance to submit their personal statements for individual feedback. Breakfast, lunch, and coffee breaks 


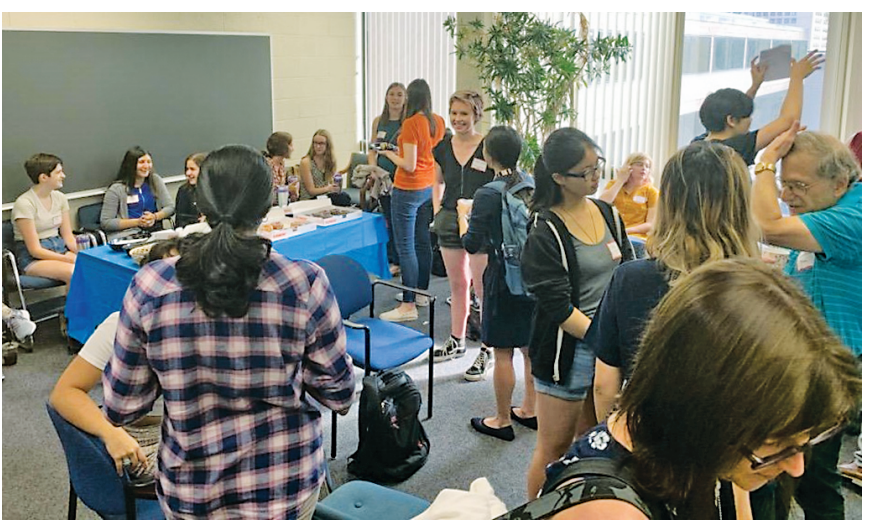

Figure 2. Participants and organizers are conversing during lunch break.

left enough time for participants to get to know each other and share experiences.

We had about 30 participants from various institutions from the US and Canada, both large state schools and small liberal arts colleges; about half were seniors and half were in their first three years of college. Feedback from the participants was overwhelmingly positive. This includes personal comments at the end of the day, email we received in the days after, and feedback shared through a Google form that we had asked the participants to fill out. After the event we created "Penn Pals" groups for the participants from each year who wanted to stay in touch for the purpose of sharing materials and supporting each other throughout the application process during the year in which they are applying. We believe that having such a support network can make the entire application process a lot less intimidating.

Some of the outcome was just what we had hoped. For example, more than $90 \%$ of the participants answered "yes" or "maybe" to the question of whether the workshop made them more likely to apply to math grad school. But we also learned a surprising amount about our potential applicants and gained a much better understanding of what their concerns are, and what might be holding them back from applying. Aside from general concerns about succeeding in grad school, the one topic that came up the most was finances. Does the grad student stipend cover the cost of living in a major city? Is it enough to pay off student loans? And finally, students admitted that they can only apply to a handful of grad schools because of the fees. Many of them did not know they could ask for waivers (at most places, including Penn and Rutgers).

From the very beginning, we viewed WOMAN UP as a pilot for future events aimed at a broader audience. For the pilot we chose an audience where we felt that our own experiences can best inform what some of the barriers in pursuing a math PhD are. This year, using the feedback we got, we are planning a larger event aimed at all underrepresented groups in mathematics. The underrepresentation of certain ethnic and racial groups, as well as gender minorities, is a lot more pronounced than that of women. The low numbers of students from these groups studying STEM in undergraduate will make it more challenging to reach those who might want to pursue graduate school in mathematics, and we will need to increase our advertisement effort for this purpose. Another challenge that we face in light of the ongoing pandemic is having to give up the in-person experience, which participants certainly found very valuable, in exchange for a virtual workshop. But this will also allow us to reach a larger audience, and hopefully include a lot more participants than we would have been able to financially support to travel to Penn. We will make an effort to make the experience personable and virtually create small group activities where participants can interact with organizers, panelists, and each other.

We truly believe that encouraging more members of underrepresented groups to pursue graduate studies in math is essential in creating more diversity in grad school and beyond, and we hope that this article will encourage more people to run events like ours. It doesn't have to be perfect-doing something small is better than nothing. If you're thinking about it, you can find some tips below.

How to do this yourself:

- Small events or online workshops can be run with minimal funding. Make a plan and then ask your department chair for support.

- Pick your target audience and think about activities that would be most useful for them; definitely include networking activities.

- Pick a date at the beginning of application season.

- Make a website with all the necessary information and a sign-up form.

- Find people to give talks, function as panelists, or help in other ways: involve your colleagues and grad students.

- Consider partnering with another institution.

- Find out about waivers for grad school application fees at your university and elsewhere. Ask your institution to become a member of the FreeApp program: https://www.btaa.org/resources-for /students/freeapp/introduction

- Think about advertising: use mailing lists, email colleagues at undergraduate institutions with a higher percentage of students from your target group, etc. Don't be afraid to cold email potential candidates.

- Once you run a workshop, get participant feedback in order to improve future events. 


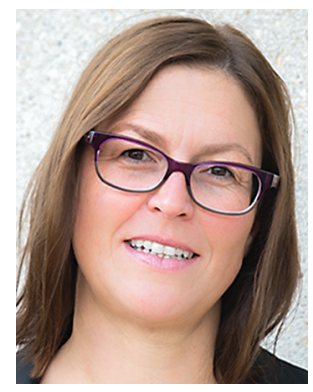

Julia Hartmann

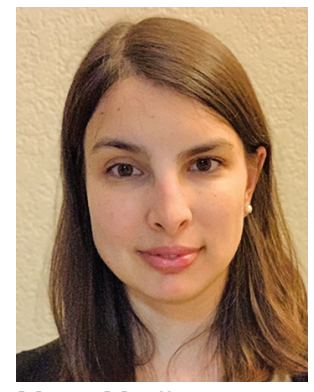

Mona Merling

\section{Credits}

Figures 1 and 2 are courtesy of Angela Gibney.

Photo of Julia Hartmann is courtesy of Steven Kasich.

Photo of Mona Merling is courtesy of Nicholas Sharac.

\section{Camp Euclid: A Research Experience for Youth-in a Virtual Environment}

\section{Juliette Benitez, Nickolas A. Castro, and David T. Gay}

\section{Introduction}

Camp Euclid is a research program for pre-college students that Euclid Lab has been running online since 2010. Students collaborate on unsolved problems in mathematics, working together online, asynchronously and in real time, with mentor facilitation.

Euclid Lab's outreach focuses on introducing unsolved research problems to the general public and especially to youth-and actively encourages people from all backgrounds to try to solve them! Two of these authors, Juliette Benitez and David Gay, founded Euclid Lab in 2010 as an independent not-for-profit mathematics research organization with Camp Euclid as its flagship outreach program. The second author, Nick Castro, has worked with Camp Euclid since 2016, first as a graduate student mentor and now as the lead senior mentor.

As we hope to inspire others to create similar programs, we would like to tell you all about Camp Euclid: how it works, why it's a great experience for students and mentors alike, and our basic philosophy behind it. See

Juliette Benitez is the associate director of Euclid Lab. Her email address is j.benitez@euc1id7ab.org.

Nickolas A. Castro is a visiting assistant professor at the University of Arkansas. His email address is nacastro@uark.edu.

David T. Gay is the director of Euclid Lab and a professor at the University of Georgia. His email address is d.gay@euc7id1ab.org.

DOI: https://dx.doi.org/10.1090/noti 2178 https://euclidlab.org/programs/camp-euclid for more details.

\section{From the Campers}

We begin with some quotes from past participants.

"I'm Ollie Thakar, currently a rising sophomore at Princeton planning to major in math, and I participated in Camp Euclid 5 years ago.... I loved the open-endedness and the fact that students were encouraged to think creatively. Camp Euclid was one of many ways I was inspired to pursue pure mathematics, and in particular I have become very interested in math pedagogy as well.... The collaboration that we faced in Camp Euclid is unlike any other I've ever encountered in math education ... making math writing better, more precise, and more rigorous is necessary yet workshopping proofs is still rare in standard education. The balance of working on one's own and with the help of others was perfect."

From Shashank Rammoorthy, now a junior at Stanford studying computer science and math: "I had a fantastic time at Camp Euclid. It was extremely motivating seeing the high-schooler researchers in my group coming up with conjectures and proving them week after week, and Camp Euclid imbued in me a love for proof-based math that continues to this day."

\section{Super-Inclusive Philosophy}

All aspects of our program, from the group structure to the mathematical content to our admissions and financial aid process, are designed to be as inclusive as possible.

\section{Student-Driven, Mentor-Inspired}

Camp Euclid is organized into groups of ideally five to seven students and three mentors. The lead mentor has a $\mathrm{PhD}$, the junior mentor is a graduate student or has a master's degree, and the assistant mentor either has or is working on a bachelor's degree.

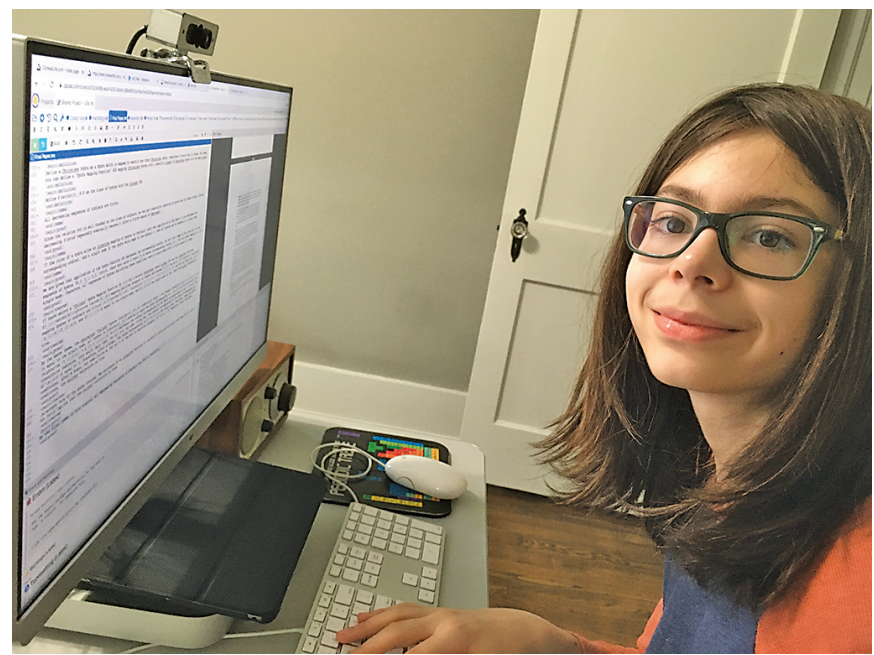

Figure 1. Current camper Mauro Araya, thinking about the Collatz conjecture. 